\title{
DISFUNÇÕES OROFACIAIS NOS PACIENTES EM TRATAMENTO ORTODÔNTICO
}

\section{Orofacial dysfunctions in pacient under orthodontic treatment}

\author{
Cristina Tostes Vieira Maciel ${ }^{(1)}$, Maristela Horta Barbosa ${ }^{(2)}$, Cláudia de Almeida Toldo ${ }^{(3)}$, \\ Fernanda Calil Borges Faza ${ }^{(4)}$, Ana Lúcia de Magalhães Leal Chiappetta ${ }^{(5)}$
}

\begin{abstract}
RESUMO
Objetivo: avaliar a necessidade de intervenção fonoaudiológica nos pacientes em tratamento na clínica ortodôntica da Universidade Federal de Juiz de Fora. Métodos: foram feitos exames clínicos, aplicação de questionário e análise de prontuários clínicos de 42 pacientes em tratamento ortodôntico na Universidade Federal de Juiz de Fora. A primeira fase do presente estudo foi composta pela avaliação da posição habitual da língua, função da respiração, deglutição e fala. Em seguida, foram obtidos dados sobre aspectos morfológicos da oclusão dentária e informações sobre a presença de hábitos orais deletérios. Resultados: notou-se que $92 \%$ dos examinados apresentavam alterações na mastigação e na deglutição e $52 \%$ tinham alguma disfunção na fala. A comparação gráfica das medidas de cada uma das variáveis sugere que há uma tendência maior a ter alteração na mastigação os indivíduos que se encontram em tratamento ordodôntico há um tempo superior ou igual a 19 meses. O mesmo já não é válido para os indivíduos que apresentaram alterações na fala e deglutição. Conclusão: Observou-se com o presente estudo a importância da intervenção fonoaudiológica, especialmente nas alterações da mastigação, na fase inicial do tratamento odontológico.
\end{abstract}

DESCRITORES: Fonoaudiologia; Ortodontia; Odontologia

\section{INTRODUÇÃO}

As estruturas rígidas e moles da cavidade oral e das regiões circunvizinhas desempenham um importante papel em funções vitais como a sucção, mastigação, deglutição, respiração, além da articulação da fala ${ }^{1}$.

Dentre essas funções, a mastigação se apresenta como uma função essencial na prevenção dos distúrbios miofuncionais, pois ela dará continuidade à estimulação da musculatura orofacial, iniciada na sucção ${ }^{2,3}$. O pro-

(1) Fonoaudióloga do Centro de Reabilitação em Odontologia Especializada; Especialista em Motricidade Oral.

(2) Fonoaudióloga do Instituto de Otorrinolaringologista e Fonoaudiologia; Especialista em Motricidade Oral.

(3) Fonoaudióloga do Instituto Médico Psico Pedagógico; Especialista em Motricidade Oral.

(4) Fonoaudióloga da Clínica Fernanda Calil, Especialista em Motricidade Oral.

(5) Fonoaudióloga do Setor de Investigação em Doenças Neuromusculares da Universidade Federal de São Paulo; Doutora em Ciências pela Universidade Federal de São Paulo. cesso da deglutição normal também é imprescindível para manter em equilíbrio as funções orais ${ }^{4}$.

Já a função respiratória normal se faz através da via aérea nasal propiciando condições favoráveis para o crescimento e desenvolvimento dos tecidos moles e duros, podendo, em presença de alguns distúrbios, ser o indivíduo um respirador oral ${ }^{3,5}$.

Por último, a fonação e a articulação compõem uma das cinco funções mais importantes da fisiologia oral ${ }^{3}$. O som produzido na laringe é controlado e moldado pela cavidade oral, faringe e cavidade nasal. A boca, portanto, desempenha um papel relevante nesse episódio ${ }^{2,3}$.

Porém, esses processos fisiológicos, quando comprometidos, podem causar ou exacerbar uma má oclusão dentária ${ }^{6}$. Essas más oclusões podem ser determinadas, portanto, por fatores hereditários, fatores pré-natais, fatores pós-natais intrínsecos, como perdas precoces e hipoplasias, e, ainda, por fatores pós-natais extrínsecos, que se referem a todos os hábitos nocivos, como a sucção sem fins nutritivos, distúrbios respiratórios, interposição lingual, alterações na deglutição, mastigação e articulação da fala ${ }^{7-9}$. Os hábitos, quando deletérios, interferem nas funções 
orofaciais constituindo fatores etiológicos em potencial no desequilíbrio muscular, podendo comprometer o desenvolvimento da oclusão normal, a morfologia e a função do sistema estomatognático ${ }^{8,10,11}$.

A sucção é realizada principalmente para obter alimento, todavia, quando realizada sem fins nutritivos pela prática repetitiva, pode condicionar a instalação do hábito deletério, permitindo o surgimento de várias alterações morfológicas e funcionais nos pacientes portadores de tais hábitos. Já o hábito de morder sem fins nutritivos pode ser extensão do hábito de sucção, ou seja, à medida que o impulso da sucção se abranda, a necessidade de apreensão vai gradativamente aumentando. Por isso, os hábitos como sucção de dedos ou chupeta podem ainda ser substituídos por onicofagia, bruxismo e/ou outros hábitos de morder, como morder lábio, bochechas, ou objetos diversos ${ }^{8,9}$.

A respiração oral é o hábito de conseqüências mais graves para a oclusão, pois as deformações por ela causadas, na maioria das vezes, são irreparáveis ${ }^{6}$. Ela pode ser descrita como "síndrome da obstrução temporária", no sistema estomatognático, devido a amplitude de sinais e sintomas que determinará, podendo ser um dos fatores causais de uma má oclusão Classe II $1^{\underline{a}}$ divisão e subdivisões ${ }^{6}$.

Alterações de fala e de deglutição também se encontram intimamente relacionadas com alguns casos de má oclusão. Assim sendo, se a língua permanece entre os dentes, esses não poderão atingir a posição de contato, levando a más oclusões dentárias, em especial, protrusão dos incisivos, má oclusão Classe II de Angle e mordida aberta anterior ${ }^{12,13}$.

Desta forma, a terapia miofuncional é freqüentemente descrita para corrigir interferências linguais durante a deglutição, com a expectativa de se reduzir espontaneamente a mordida aberta anterior ${ }^{5}$.

A associação entre ortodontistas e fonoaudiólogos é de suma importância, visto que a função dos aparelhos ortodônticos ou ortopédicos limita-se a alterar a disposição dos arcos dentários, enquanto a terapia fonoaudiológica irá trabalhar a reabilitação miofuncional orofacial, que visa a modificação das funções orofaciais alteradas ${ }^{14}$.

O objetivo dessa pesquisa é identificar as alterações nas funções orofaciais e suas implicações em pacientes da clínica ortodôntica da Universidade Federal de Juiz de Fora.

\section{MÉTODOS}

Participaram deste estudo 42 pacientes, de ambos os gêneros, provenientes da Clínica Ortodôntica da Faculdade de Odontologia da Universidade Federal de Juiz de Fora/MG.

O critério de inclusão adotado foi a constatação de paciente em tratamento ortodôntico que se encontra na dentição permanente. Foram excluídos da amostra pacientes que se encontravam em tratamento fonoaudiológico e portadores de síndromes.

Foi desenvolvido um estudo exploratório composto por três etapas: questionário, exames da oclusão dentária e exame fonoaudiológico.

O questionário elaborado pelas autoras, foi aplicado nos pacientes com a finalidade de obter informações sobre a presença de hábitos orais deletérios (Figura 1).

No exame da oclusão dentária foram avaliados os aspectos morfológicos da oclusão, realizado por um cirurgião-dentista por meio de inspeção clínica, com auxílio de espátulas e luvas descartáveis. Foi investigada a classificação de Angle ${ }^{13}$ em que se enquadra o paciente e os padrões transversais (mordida cruzada) e longitudinais (mordida aberta ou sobremordida) (Figura 2).

O exame fonoaudiológico foi composto pela avaliação da posição habitual da língua, função da respiração, deglutição e fala, para que se identificassem os padrões orais dos pacientes (Figura 3).

No exame da função respiratória foram observadas: postura corporal, postura de lábios e mandíbula, forma de sentar-se, existência de algum ponto de vedamento da cavidade oral, além da manutenção dos lábios entreabertos em situação de descontração. Também foi utilizado o Espelho de Glatzel em que foram observadas a capacidade de respiração nasal e a simetria desta função nas narinas. Foi pedido ao paciente que não modificasse o seu modo de respirar no momento em que fosse colocado o espelho, mantendo-o por alguns segundos para a confirmação dos resultados. O teste foi refeito após o paciente ter assoado o nariz de maneira fisiológica ${ }^{15}$.

O exame da deglutição foi feito com água e pão francês amanhecido e observado sem tocar no examinado se houve projeção de língua e participação da musculatura perioral, como contração dos lábios e do músculo mentual. Para não causar um desequilíbrio no processo de deglutição, encobrindo um tipo de deglutição que não é real, os lábios não foram abertos na primeira fase da deglutição, pois ao separar os lábios altera-se a pressão da cavidade oral, causando um desequilíbrio no processo de deglutição ${ }^{15}$.

A fala foi avaliada através da conversa espontânea e da fala dirigida em que foi pedido ao paciente para repetir palavras, a fim de observar a presença de alguma deficiência articulatória na produção dos fonemas, mais precisamente distorções ${ }^{15}$.

Esta pesquisa foi avaliada e aprovada com o número 127/5 pelo Comitê de Ética e Pesquisa do Centro de Especialização em Fonoaudiologia Clínica.

Os dados obtidos na pesquisa são apresentados em forma descritiva através de freqüências relativas. As associações entre as variáveis independentes e dependentes (funções orofaciais) estudadas foram determinadas pelo Teste Exato de Fisher, alternativo 
ao teste $\div^{2}$, para freqüências esperadas inferiores a 5. Foram consideradas significativas associações com $p$-valor $<0,05$. A variável independente do tempo de tratamento foi transformada em variável categórica, tendo a mediana de 19 meses com ponto de corte para cumprir os pressupostos do teste aplicado.

\section{RESULTADOS}

A idade dos pacientes variou de 12 a 33 anos, com média de 15, 4 anos e média do tempo de tratamento 28,5 meses (3-68 meses). Vinte e dois indivíduos (52\%) eram do gênero masculino e vinte (48\%) do feminino.

Quanto à análise da avaliação dos hábitos nocivos, observou-se que o hábito de morder objetos foi o mais freqüente, acometendo $38,1 \%$ da amostra; seguido dos hábitos de ranger dentes (33,3\%), morder lábios $(26,2 \%)$, roer unhas $(23,8 \%)$ e morder bochechas (19\%), conforme visto na Tabela 1.

Com base nas classificações das más oclusões de Angle, diagnosticou-se que 33\% apresentaram Classe I, $50 \%$ Classe II, $7 \%$ Classe III. Os 10\% restantes não se enquadraram na Classificação de Angle, conforme indicado na Tabela 2.

As principais más oclusões, identificadas na amostra, foram mordida aberta anterior, sobremordida exagerada, mordida cruzada anterior, mordida cruzada posterior, sobressaliência exagerada e topo a topo anterior $(28,6 \%, 14,3 \%, 11,9 \%, 7,1 \%, 2,4 \%$ e $2,4 \%$ respectivamente), conforme indicado na Tabela 3.

$\mathrm{Na}$ avaliação da função respiratória dos examinados, foi constatado que 57\% apresentaram respiração nasal, seguida por $26 \%$ com respiração oronasal e $17 \%$ com respiração oral.

No que se referiu às funções comprometidas, não se notou significância entre o tempo de tratamento (mediana de 19 meses, utilizada como ponto de corte para categorização da variável) e o aumento da freqüência de alterações na deglutição $(p=0,78)$ ou fala $(p=0,33)$. Mas na mastigação foi significante que quanto menor o tempo de tratamento maior era a freqüência de alterações nesta função $(p=0,02)$.

Foi identificada associação significativa entre a presença de hábitos deletérios, especialmente o hábito de morder bochechas, e a ocorrência de deglutição atípica $(p=0,01)$, bem como alteração das funções musculares $(p=0,02)$. Já o padrão de respiração não expressou o mesmo comportamento $(p=0,06)$ com relação à deglutição.

Analisando os dados obtidos na função de mastigação, foi constatado que a mastigação bilateral foi predominante, aparecendo em $76,9 \%$ dos indivíduos avaliados (Tabela 5). A participação da musculatura perioral foi encontrada em $59 \%$ dos sujeitos e a interposição de lábio inferior em 7,7\%, conforme mostra a Tabela 6. Quanto aos lábios, observou-se $7,7 \%$ abertos e $92,3 \%$ fechados.

Quanto aos movimentos mandibulares realizados durante a mastigação, observou-se uma predominância de movimentos rotatórios de mandíbula $(74,4 \%)$ sobre os movimentos verticais $(25,6 \%)$.

Em relação ao tipo mastigatório constatou-se que $33,3 \%$ dos indivíduos apresentaram mastigação lenta, $30,8 \%$ mastigação rápida e 2,6\% mastigação ruidosa.

De acordo com a Tabela 8, os fatores mais referidos durante a avaliação da deglutição foram participação da musculatura perioral $(43,6 \%)$, projeção anterior da cabeça $(10,3 \%)$ e projeção anterior de língua $(7,4 \%)$.

No que tange à análise da avaliação da fala, observou-se que não houve registro de omissões ou substituições. A interposição de língua foi a alteração da fala mais freqüente, acometendo $79,8 \%$ da amostra conforme Tabela 9.

A Figura 4 mostra um dos indivíduos da amostra fazendo projeção de língua durante a fala.

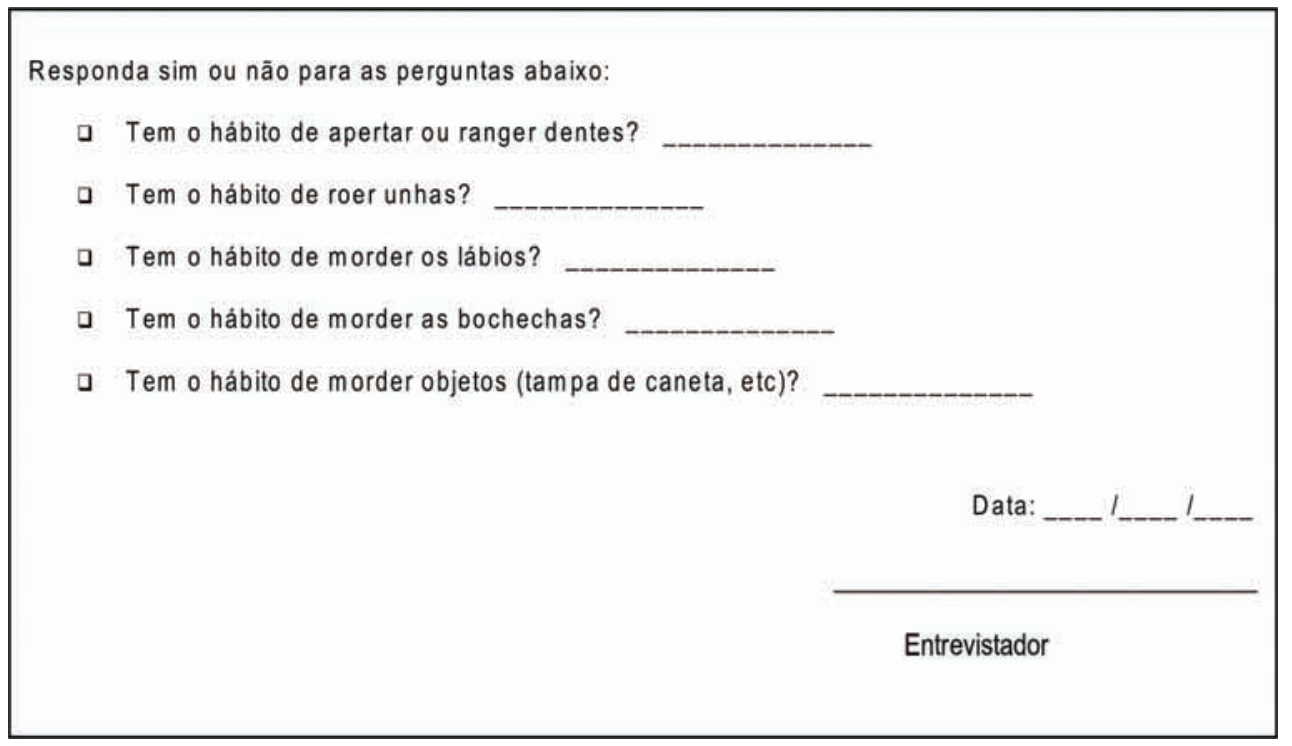

Figura 1 - Proposta de questionário para levantamento de informações acerca de hábitos deletérios 


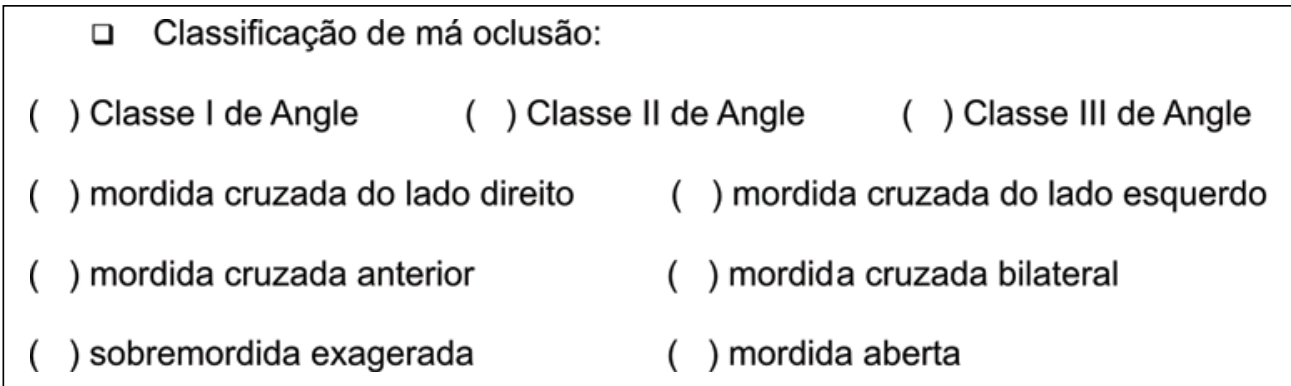

Figura 2 - Avaliação odontológica

\begin{tabular}{|ll|}
\hline Funções: & $\underline{\text { Deglutição: }}$ \\
Respiração: & $($ ) normal \\
( ) nasal ( ) oral ( ) oronasal & $($ ) alterada \\
Mastigação: & $($ ) projeção anterior de língua \\
( ) normal & $($ ) projeção lateral de língua \\
( ) alterada & $($ ) participação da musculatura perioral \\
( ) bilateral & $($ ) projeção da cabeça \\
( ) unilateral direita & $($ ) engasgo \\
( ) unilateral esquerda & $($ ) interposição de lábio inferior \\
( ) lenta & $($ ) ruidosa \\
( ) rápida & $\underline{\text { Fala: }}$ \\
( ) ruidosa & $($ ) normal \\
( ) lábios fechados & $($ ) sigmatismo interdental \\
( ) lábios abertos & $($ ) sigmatismo lateral \\
( ) interposição de lábio inferior & $($ ) interposição de língua anterior \\
( ) participação exagerada da musculatura perioral & $($ ) acúmulo de saliva nas comissuras \\
( ) movimentos rotatórios da mandíes \\
( ) movimentos verticais da mandíbula & $($ ) outro \\
\hline
\end{tabular}

Figura 3 - Avaliação fonoaudiológica 


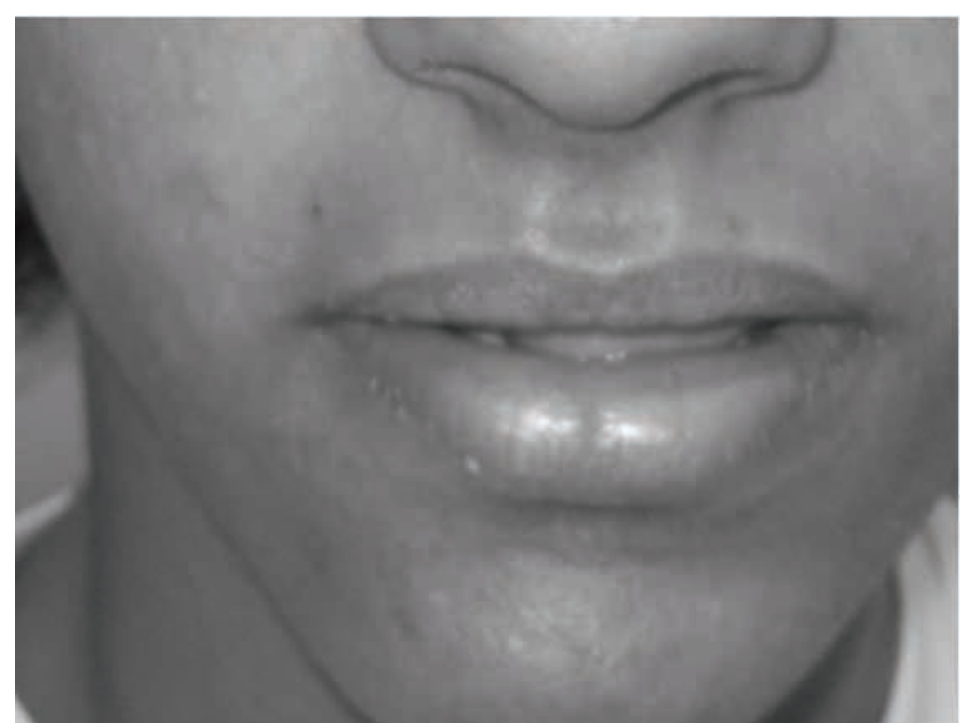

Figura 4- Sujeito da pesquisa apresentando a projeção de língua durante a fala

Tabela 1 - Distribuição dos achados clínicos da avaliação de hábitos nocivos

\begin{tabular}{l|c|c}
\hline \multicolumn{1}{c|}{$\begin{array}{c}\text { Hábitos } \\
\text { nocivos }\end{array}$} & Valores absolutos & Freqüência (\%) \\
\hline Morder bochechas & 8 & 19 \\
\hline Roer unhas & 10 & 23,8 \\
\hline Morder lábios & 11 & 26,2 \\
\hline Ranger dentes & 14 & 33,3 \\
\hline Morder objetos & 16 & 38,1 \\
\hline
\end{tabular}

Tabela 2 - Distribuição dos indivíduos em relação à classificação de Angle

\begin{tabular}{l|c|c}
\multicolumn{1}{c|}{$\begin{array}{c}\text { Classificação } \\
\text { de Angle }\end{array}$} & Valores absolutos & Freqüência (\%) \\
\hline Classe I & 14 & 33 \\
\hline Classe II & 21 & 7 \\
\hline Classe III & 3 & 10 \\
\hline Não classificado & 4 & \\
\hline
\end{tabular}


Tabela 3 - Distribuição dos achados na avaliação referentes às anomalias de oclusão

\begin{tabular}{l|c|c}
\hline \multicolumn{1}{c|}{ Má oclusão } & Valores absolutos & $\begin{array}{c}\text { Freqüência (\%) de pacientes } \\
\text { portadores da má oclusão }\end{array}$ \\
\hline Topo a topo anterior & 1 & 2,4 \\
\hline Sobressaliência & 1 & 2,4 \\
exagerada & 3 & 7,1 \\
\hline Mordida cruzada & & 11,9 \\
posterior & 5 & 14,3 \\
\hline Mordida cruzada anterior & 6 & 28,6 \\
\hline Sobremordida exagerada & 12 & \\
\hline Mordida aberta anterior & & \\
\hline
\end{tabular}

Tabela 4 - Análise das funções orais normais e alteradas em relação ao tempo de tratamento

\begin{tabular}{|c|c|c|c|}
\hline Função & $\begin{array}{l}\mathrm{N}^{\circ} \text { de casos com } \\
\text { tempo de tratamento } \\
\text { inferior a } 19 \text { meses }\end{array}$ & $\begin{array}{l}\mathrm{N}^{\circ} \text { de casos com } \\
\text { tempo de tratamento } \\
\text { superior ou igual a } \\
19 \text { meses }\end{array}$ & $\begin{array}{c}\text { p-valor segundo } \\
\text { Teste Exato de } \\
\text { Fisher }\end{array}$ \\
\hline \multicolumn{4}{|l|}{ Deglutição } \\
\hline normal & 4 & 1 & 0,07 \\
\hline alterada & 18 & 19 & \\
\hline \multicolumn{4}{|l|}{ Fala } \\
\hline normal & 10 & 9 & 0,33 \\
\hline alterada & 12 & 11 & \\
\hline \multicolumn{4}{|c|}{ Mastigação } \\
\hline normal & 1 & 3 & 0,02 * \\
\hline alterada & 21 & 17 & \\
\hline
\end{tabular}


Tabela 5- Distribuição dos achados referentes à avaliação funcional da mastigação

\begin{tabular}{l|c|c}
\hline \multicolumn{1}{c|}{$\begin{array}{c}\text { Padrão } \\
\text { mastigatório }\end{array}$} & Valores absolutos & $\begin{array}{c}\text { Freqüência (\%) dentre os que } \\
\text { apresentavam alteração }\end{array}$ \\
\hline Unilateral esquerda & 4 & 10,3 \\
\hline Unilateral direita & 5 & 12,8 \\
\hline Bilateral & 30 & 76,9 \\
\hline
\end{tabular}

Tabela 6- Distribuição dos achados referentes à avaliação das alterações mais freqüentes da mastigação

\begin{tabular}{l|c|c}
\hline \multicolumn{1}{c|}{$\begin{array}{c}\text { Alterações mais } \\
\text { freqüentes } \\
\text { da mastigação }\end{array}$} & Valores & Freqüência (\%) dentre os \\
& absolutos & portadores de alterações \\
\hline Interposição de lábio inferior & 3 & 7,7 \\
\hline Participação da muscutatura & 23 & 59 \\
perioral & & \\
\hline
\end{tabular}

Tabela 7- Distribuição dos achados referentes à descrição do tipo de mastigação

\begin{tabular}{l|c|c}
\hline \multicolumn{1}{c|}{$\begin{array}{c}\text { Tipo de } \\
\text { mastigação }\end{array}$} & Valores absolutos & Freqüência (\%) \\
\hline Ruidosa & 1 & 2,6 \\
\hline Rápida & 13 & 30,8 \\
\hline Lenta & 14 & 33,3 \\
\hline Normal & 14 & 33,3 \\
\hline
\end{tabular}


Tabela 8 - Distribuição dos achados referentes aos achados clínicos encontrados na deglutição

\begin{tabular}{l|c|c}
\hline \multicolumn{1}{c|}{$\begin{array}{c}\text { Alterações da } \\
\text { deglutição }\end{array}$} & Valores absolutos & $\begin{array}{c}\text { Freqüência (\%) dentre os } \\
\text { paciente com alteração da } \\
\text { deglutição }\end{array}$ \\
\hline Engasgos & 1 & 2,6 \\
\hline Interposição de lábio & 2 & 5,1 \\
inferior & & \\
\hline Projeção anterior de língua & 3 & 7,4 \\
\hline Projeção de cabeça & 4 & 43,6 \\
\hline Musculatura perioral & 17 & \\
\hline
\end{tabular}

Tabela 9 - Distribuição dos achados referentes á descrição das alterações de fala encontradas nos indivíduos

\begin{tabular}{l|c|c}
\hline \multicolumn{1}{c|}{ Alterações da fala } & Valores absolutos & $\begin{array}{c}\text { Freqüência (\%) dentre os } \\
\text { portadores de alterações } \\
\text { na fala }\end{array}$ \\
\hline Sigmatismo interdental & 1 & 4,2 \\
\hline Laterização para direita & 2 & 8,3 \\
\hline Laterização para esquerda & 4 & 16,7 \\
\hline Acúmulo de saliva & 4 & 16,7 \\
\hline Sigmatismo lateral & 6 & 25 \\
\hline Interposição anterior de língua & 17 & 79,8 \\
\hline
\end{tabular}

\section{DISCUSSÃO}

Compreender os aspectos morfofisiológicos do sistema estomatognático e suas patologias, assim como entender os estágios da dentição e sua classificação quanto ao tipo de oclusão torna-se relevante ao se analisar os resultados da pesquisa feita com os pacientes da Universidade Federal de Juiz de Fora, uma vez que se percebe uma relação entre funções orofaciais e articulação da fala com suas alterações.
Pôde-se constatar, por exemplo, que entre os 42 examinados, 39 apresentavam algum tipo de distúrbio na deglutição, 39 alguma alteração na mastigação e 22 deficiências articulatórias na fala, sendo que alguns pacientes estavam incluídos em mais de uma alteração.

Os pacientes examinados no presente estudo estavam na faixa etária entre 12 e 33 anos e a maior parte deles apresentava algum tipo de hábito oral, sendo o mais freqüente o de morder objetos apresentado por 
$38,1 \%$ dos pacientes. Isso mostra que pode ter havido a interferência de tais hábitos nos padrões de mastigação e deglutição, na tentativa de se obter uma ação compensatória quanto ao efeito daqueles hábitos sobre o processo alveolar e sobre os dentes ${ }^{13}$.

Assim sendo é importante destacar o papel do fonoaudiólogo em adequar a função da fala para que não haja caso de recidiva, devido a um mau posicionamento de língua pós-tratamento ortodôntico. Salienta-se, pois, neste estudo, os padrões de deglutição, mastigação e respiração relacionados com a má oclusão e suas conseqüências nas alterações da fala.

No presente trabalho, não foi ratificada a informação do autor ${ }^{12}$ quanto ao padrão de deglutição e o tempo de tratamento ortodôntico. Em uma associação estatística não significativa de $(p=0,7)$, a hipótese de que o tempo de tratamento influiria na forma de deglutição foi refutada. Porém deve-se examinar com cuidado esses dados, uma vez que tanto a freqüência absoluta como a relativa de casos com alterações na deglutição foram pequenas. Um universo amostral maior seria essencial para se fazer uma inferência sobre $o$ assunto.

A deglutição atípica pode decorrer de duas situações: como hábito, para reduzir as aberturas funcionais na região anterior do alvéolo; ou como resultado das acomodações esqueletais, no caso das mordidas abertas esqueléticas ${ }^{16}$. Por outro lado, a má oclusão, independente de ser proveniente de um hábito nocivo, é que irá ditar o posicionamento da língua. O trabalho mostrou uma alta freqüência das alterações na deglutição, atingindo $93 \%$ dos pacientes examinados.

Seguindo esta posição, a deglutição atípica (com interposição de língua) foi descrita como sendo uma adaptação útil quando está presente uma mordida aberta ou sobressaliência; ou seja, quase todo indivíduo com mordida aberta apresenta interposição de língua, não sendo a recíproca verdadeira ${ }^{6}$, o que confirma os achados da pesquisa que constatou apenas dos indivíduos, dos 42 examinados, apresentando este padrão patológico vertical de oclusão.

Um resultado previsível e corroborado pelo presente estudo foi a relação existente entre os hábitos parafuncionais com a deglutição atípica ${ }^{15}$. Foi relatado que esses hábitos podem fazer com que a língua fique na transição entre a margem gengival e os dentes, deformando a arcada dentária, alterando a fala da criança, podendo, ainda, se tornar um apoio ou refúgio em situações de frustrações emocionais. É tão grande a importância deste padrão de deglutição no desenvolvimento das más oclusões que foi preconizado a remoção do hábito em primeiro lugar, antes da reeducação do paciente quanto ao modo de deglutir ${ }^{17}$.

As funções estomatognáticas, corretamente executadas são essenciais na prevenção dos distúrbios miofuncionais, pois segundo a literatura ${ }^{18}$ este pro- cesso será imprescindível para uma estimulação normal da musculatura orofacial. Uma investigação da ação do tratamento ortodôntico sobre a função mastigatória é tão imperiosa, pois este passa a ser de grande importância na adaptação e/ou remodelamento da musculatura orofacial ${ }^{6}$. Foi demonstrada a forte significância estatística entre os tempos de tratamento ortodôntico e a função de mastigação $(p=0,02)$, onde se notou, surpreendentemente, que quanto menor era o tempo de tratamento, maior era a freqüência de alterações nessa função. Isso implica em dizer que mesmo nas fases mais incipientes do tratamento já há uma mudança significativa na dinâmica muscular estomatognática.

Apenas pequena parte da amostra de pacientes possuía um padrão respiratório oral (17\%), sendo que a respiração oronasal foi bastante freqüente (26\%). A respiração oral, muitas vezes, pode causar um crescimento vertical excessivo da maxila, fazendo com que uma má oclusão de Classe II se instale ${ }^{12}$. Em um estudo realizado ${ }^{19}$ para analisar a função respiratória de pacientes com diferentes tipos de padrões de deglutição foi constatado que as crianças que mais apresentavam deglutição atípica eram justamente as respiradoras orais e possuidoras de uma mordida aberta, mas esses achados não foram corroborados pelo presente trabalho que não encontrou significância estatística entre os fatores acima.

A literatura ressalta que, quando a criança passa a respirar pela boca, a língua posiciona-se diferentemente na cavidade oral para a proteção das tonsilas palatinas e orofaringe, deixando assim de cumprir o seu papel modelador dos arcos dentários. Com isso, a língua estimulará o crescimento maxilar anteriormente levando a uma Classe II, inibindo também o crescimento mandibular. Além disso, poderá se interpor entre as arcadas, mantendo-as afastadas, causando uma mordida aberta anterior ${ }^{20}$.

Os casos de Classe II com grande sobressaliência e grande sobremordida sempre estão associados com uma interposição labial durante a deglutição. Nesses casos, a hiperatividade do lábio inferior produz o selamento da cavidade oral com as faces linguais dos incisivos superiores ${ }^{18}$. A impossibilidade dos lábios superior e inferior se tocarem, gera o padrão de deglutição alterado. Esse caso é apenas uma adaptação funcional dos músculos periorais à má oclusão. Nota-se, então, a contração do músculo orbicular dos lábios e principalmente do músculo mentual. Ao se corrigir a má oclusão, o problema cessará ${ }^{19}$. A associação entre os hábitos nocivos, ou hábitos orais não nutritivos com a função muscular alterada reportada nos achados da pesquisa, associação estatisticamente significante entre a presença de hábitos deletérios, especialmente o hábito de morder bochechas, e a ocorrência de deglutição atípica $(p=0,01)$, bem como alteração das funções musculares $(p=0,02)$, sugerem 
a existência desta associação. Contudo, a literatura sugere que esta alteração ocorra devido à adaptação funcional muscular em virtude da má oclusão, que pode, ou não, ter sido causada pelo hábito nocivo. $O$ trabalho presente mostrou que dentre os pacientes $(\mathrm{n}=42), 39$ apresentavam alterações na deglutição, justificando os $43,6 \%$ encontrados nos pacientes com participação da musculatura perioral. Um diagnóstico diferencial deve ser tomado quando o problema persistir após a correção da má oclusão. Neste caso a contração do músculo mentual se mantém mesmo sem a necessidade do selamento anterior ${ }^{20}$.

$\mathrm{Na}$ articulação das palavras, as más oclusões desempenham fator decisivo, pois a posição da língua é também ditada pelo padrão esquelético. Numa Classe III, a língua tende a se posicionar abaixo do plano de oclusão. Nas Classes II, ela se posiciona anteriormente. Ou ainda, acreditase que esta postura protuída da língua pode resultar em uma mordida aberta ${ }^{18}$. As faces dolicocefálicas com projeção de língua são grandes candidatas a apresentar uma mordida aberta anterior ${ }^{18}$. Há quase sempre uma má oclusão ditando o posicionamento da língua. Mas deve-se levar em conta que nos casos de macroglossia, a própria língua pode ser fundamental no aparecimento da má oclusão, não sendo apenas uma conseqüência. As alterações na fala estavam pre- sentes em 22 pacientes, correspondendo a $52 \%$ dos examinados, sendo que as alterações que se destacaram foram a interposição anterior correspondendo a $79 \%$ de todas as alterações e o sigmatismo lateral, correspondendo a $25 \%$.

Em decorrência do que foi discutido anteriormente, é essencial a interação entre ortodontistas e fonoaudiólogos e uma intervenção para se alcançar uma reabilitação significativa do paciente, inclusive nas fases iniciais do tratamento.

Convém salientar que alguns resultados deste estudo podem ter sido influenciados pelo tamanho da amostra, gerando, especialmente, intervalos de confiança amplos, ou medidas de associação não atingindo significância estatística. Abre-se, portanto, um espaço para pesquisas posteriores.

\section{CONCLUSÃO}

Mediante análise dos dados do presente estudo é possível concluir que:

Não houve relação significante entre o tempo de tratamento e o aumento da freqüência de alterações na deglutição e fala.

A função da mastigação é influenciada pelo tempo de duração do tratamento ortodôntico, se apresentando mais alterada nos indivíduos que estavam em tratamento há menos tempo.

\begin{abstract}
Purpose: to evaluate the need for speech therapy intervention in patients treated in the orthodontic clinic of the Federal University of Juiz de Fora. Methods: clinical examinations, application of questionnaire and clinical medical register analysis of 42 patients under orthodontic treatment in the Federal University of Juiz de Fora had been carried out. The first phase of this study was made up by the evaluation of the habitual tongue position, breathing function, deglutition and speech. Soon afterwards, data were obtained on morphologic aspects of the dental occlusion and information on the presence of deleterious oral habits. Results: one noticed that $92 \%$ of the examined ones presented alterations in the chew and the deglutition and $52 \%$ had some speech dysfunction. The graphical comparison of the measures for each variable suggests that it has the highest trend to have alteration in the chew in the individuals that are in orthodontic treatment for 19 months or above. The same is yet not valid for the subjects that showed alterations in speech and deglutition. Conclusion: the importance of speech intervention was noted in this study, especially in the alterations in chewing, the initial phase of orthodontic treatment.
\end{abstract}

KEYWORDS: Speech, Language and Hearing Sciences; Orthodontics; Dentistry

\section{REFERÊNCIAS}

1.Felício CM. Desenvolvimento normal das funções estomatognáticas. In: Ferreira LP, Befi-Lopes DM, Limongi SCO, organizadores. Tratado de fonoaudiologia. São Paulo: Roca; 2004. p. 195-211.

2. Macedo EDM, Gomes GF, Furkim AM. Manual de cuidados do paciente com disfagia. São Paulo: Lovise; 2000. p. 19-27.
3. Kurame M, Tavares SW, Almeida HA, Almeida MHC, Nöuer DF. Correção da deglutição atípica associada à mordida aberta anterior: relato de cãso clínico. J Bras Ortodont Ortop Facial. 2001; 6(36):493-501.

4.Proffit WR. Ortodontia contemporânea. 3. ed. Rio de Janeiro: Guanabara Koogan; 2002. p. 105-37. 5. Barreto EPR, Faria MMG, Castro PRS. Hábitos bucais de sucção não nutritiva, dedo e chupeta: abordagem multidisciplinar. J Bras Fonoaudiol. 2003; 4(16):6-12. 
6.Ando T. Fatores pós-natais intrínsecos e extrínsecos de interesse para ortodontia preventiva. In: Pinto ACG. Odontopediatria. São Paulo: Santos; 2000. p. 739-66.

7.Saito M. A study on improving tongue functions of open-bite children at the mixed dentition period: modifications of a removable habit-breaker appliance and their sonographic analysis. Kokubyo Gakkai Zasshi. 2001; 68(2):193-207.

8.Carvalho DS. Fatores hereditários determinantes das maloclusões. In: Pinto ACG. Odontopediatria. São Paulo: Santos; 2000. p. 721-30.

9. Ramos JML, Reis MCS; Serra-Negra JMC. Como eliminar os hábitos de sucção não nutritiva? J Bras Fonoaudiol. 2000; 1(3):21-7.

10. Yamaguchi $\mathrm{H}$, Sueishi K. Malocclusion associated with abnormal posture. Bull Tokyo Dent Coll. 2003; 44(2):43-54.

11. Lino AP. Fatores extrínsecos determinantes de maloclusões. In: Pinto ACG. Odontopediatria. São Paulo: Santos; 2000. p. 767-75.

12. Nobre DG, Gushiken FT, Periotto MC, Araújo RH. A integracäo entre a fonoaudiologia e a odontologia no respirador bucal: a relação com maloclusäo do tipo Classe II de Angle e o seu tratamento. Rev Paul Odontol. 2004; 2(26):4-11.

13. Junqueira P. Avaliação miofuncional. In: Marchesan
IQ. Fundamentos em fonoaudiologia: aspectos clínicos da motricidade oral. Rio de Janeiro: Guanabara Koogan; 1998. p. 13-21.

14. Fujiki T, Inoue M, Miyawaki S, Nagasaki T, Tanimoto K, Takano-Yamamoto T. Relationship between maxillofacial morphology and deglutitive tongue movement in patients with anterior open bite. Am J Orthod Dentofacial Orthop. 2004; 125(2):160-7. 15. Stahl F, Grabowsky R. Orthodontic findings in the deciduous and early mixed dentition: inferences for a preventive strategy. J Orofac Orthop. 2003;64(6):401-16. 16. Zardetto CG, Rodrigues CR, Stefani FM. Effects of different pacifiers on the primary dentition and oral myofunctional structures of preschool children. Pediatr Dent. 2002; 24(6):552-60.

17. Faria PT, Ruellas ACO, Matsumoto MA, AnselmoLima WT, Pereira FC. Dentofacial morphology of mouth breathing children. Braz Dent J. 2002; 13(2):129-32.

18. Tanigute CC. Desenvolvimento das funções estomatognáticas. In: Marchesan IQ. Fundamentoos em fonoaudiologia: aspectos clínicos da motricidade oral. Rio de Janeiro: Guanabara Koogan; 1998. p. 1-6. 19. Marchesan IQ. Fundamentos em fonoaudiologia: aspectos clínicos da motricidade oral. Rio de Janeiro: Guanabara Koogan; 1998. p. 151-8.

20. Moyers R. Ortodontia. 4. ed. Rio de Janeiro: Guanabara Koogan; 1991. p. 175-467.

Recebido em: 13/07/2006

Aceito em: 15/10/2006

Endereço para correspondência:

Rua Itamar Soares de Oliveira, 56 / 403

Juiz de Fora - MG

CEP: $36033-280$

Tel: (32) 32361705 / 99029212

E-mail:cristostesmaciel@bol.com.br 